\title{
0 compadrio na formação das capitanias hereditárias da mídia brasileira
}

\section{Álvaro Nunes Larangeira}

\section{Resumo}

Valendo-se, como analogia, da política das capitanias hereditárias adotada pela coroa portuguesa como processo de colonização do território brasileiro no século XVI e a distribuição das mesmas conforme o parentesco e apadrinhamento com o poder real, este artigo destaca a presença do compadrio entre o poder público e o jornalismo desde a gênese da imprensa no Brasil, com a Gazeta do Rio de Janeiro e o Correio Braziliense, em 1808, até os contemporâneos conglomerados midiáticos, aqui expostos os casos dos Diários Associados e, em especial, das Organizações Globo. 0 objetivo é mostrar quão questionáveis foram e são as propaladas retóricas de independência tão ao gosto dos veículos de comunicação e da imprensa brasileira.

Palavras-chave

Compadrio. Capitanias hereditárias. Mídia brasileira. Jornalismo. Formação.

Álvaro Nunes Larangeira | alvarolarangeira@hotmail.com Universidade Tuiuti do Paraná/UTP. Pós-doutor em jornalismo pela Universidade de Coimbra, como bolsista do CNPq. Pesquisador $P Q 2$. Doutor e mestre em Comunicação Social pela PUC-RS e professor adjunto no Doutorado e Mestrado em Comunicação e Linguagens da Universidade Tuiuti do Paraná. Autor do livro Comunicação Monoteísta, ensaio no qual propõe a Comunicação Monoteísta como uma teoria da comunicação.

\section{As primeiras capitanias do Brasil}

A efetiva colonização do território brasileiro por Portugal inicia-se em fevereiro de 1534 quando o rei lusitano D. João III - pressionado pelas incursões francesas e piratas à costa para, principalmente, o espólio da madeira do pau-brasil, utilizada na construção de móveis e navios; pelas pretensões da Espanha em também se instalar nas terras avistadas por Pedro Álvares Cabral em 1500; e pela debilidade econômica do reino - resolve-se pela adoção do sistema das capitanias hereditárias. Eram lotes de terra com 150 a 600 quilômetros de largura cedidos a pessoas físicas e divididos na extensão delimitada pela linha imaginária do Tratado de Tordesilhas, compreendendo de Belém, no Pará, a Laguna, em Santa Catarina. Nas três décadas anteriores, entre 1500 e 1530, Portugal tentara primeiro controlar a colônia recém-encontrada por meio de feitorias. No período de 1500 a 1505, a coroa portuguesa arrendou o Brasil a um grupo de comerciantes lisboetas liderados por Fernão de Noronha, garantindo a estes o monopólio comercial. Em troca, exigia do 
consórcio o envio de expedições exploratórias pelo litoral meridional.

0 acordo durou cinco anos, com a retomada do controle pelo reino português. Fernão de Noronha, no entanto, foi contemplado em 1504 pelo rei da época, Dom Manuel I, com uma capitania, a de São João (hoje Fernando de Noronha), antecipando a política da coroa a ser implementada 30 anos depois. 0 sistema das capitanias era recorrente pela monarquia lusitana na conquista ultramarina. Fora experimentado em outras possessões. Havia os casos dos Açores e Madeira, próximos ao litoral europeu, do arquipélago São Tomé e Príncipe, na costa da Guiné Equatorial, na África, e inclusive no território luso, no Alentejo e Algarve, logo em seguida à expulsão dos mouros em 1249.

No caso do Brasil, a decisão pelo sistema das capitanias respaldava-se na situação econômica do reino à época. Em 1532, o Conselho Real decidira em reunião no Paço de Évora repartir o Brasil dessa forma principalmente em razão das agruras financeiras pelas quais passava o tesouro real. Portugal sofria com as dívidas interna e externa, além dos gastos para a reconstrução da capital, castigada por forte terremoto no ano anterior. D. João III herdara do pai, D. Manuel, "um erário vazio e a fazenda real bastante arruinada, o que o levaria a viver em aflições de dinheiro". As intempéries naturais tampouco ajudavam: "A terra portuguesa estava esturricada por uma tremenda seca, que fizera mirrar as colheitas e trouxera a miséria e a peste". (HERCULANO, apud BUENO, 2006, p. 73).

A dívida pública alcançava os dois milhões de cruzados, engordada pelos empréstimos obtidos por D. João com os banqueiros dos Países Baixos, a juros de $15 \%$ ao ano. Valor corrosivo para uma arrecadação anual inferior a um milhão. Por pressão de Dom Antônio de Ataíde, 0 gestor do tesouro real, o conselho deliberou pela partilha das terras brasileiras à iniciativa privada. Os donatários ganhariam a posse, mas o Estado manteria o direito de propriedade, assegurado pelas cartas de doação, com a determinação da posse e a delimitação da área, e de foral, relacionando os direitos e deveres dos proprietários das capitanias.

Não podiam [os donatários] vender ou dividir a capitania, cabendo ao rei 0 direito de modificá-la ou mesmo extingui-la. A posse dava aos donatários extensos poderes tanto na esfera econômica na arrecadação de tributos como na esfera administrativa. A instalação de engenhos de açúcar, moinhos de água, assim como 0 uso de depósitos de sal, dependiam do pagamento de direitos; parte dos tributos devidos à Coroa pela exploração do paubrasil, de metais preciosos e dos derivados da pesca, cabia aos capitães donatários. Do ponto de vista administrativo, tinham o monopólio da justiça e autorização para fundar vilas, doar sesmarias [terreno não cultivado, localizado no interior da capitania], alistar coIonos para fins militares e formar milícias sob o seu comando. A atribuição de doar sesmarias deu origem à formação de vastos latifúndios (FAUSTO, 2006, p. 19). 
Empenhada em fortalecer e perpetuar a presença no Brasil - e respaldada pelo desinteresse da alta aristocracia, pelo menos dos condes, duques e infantes, pela cessão das terras em lugar tão distante e na contramão da rota comercial com o Oriente -, a Coroa "selecionou, para guardar seus vínculos públicos com a conquista, pessoas próximas do trono, burocratas e militares, letrados ou guerreiros provados na Índia, pequena nobreza, sedenta de glórias e riquezas" (CAPISTRANO DE ABREU, apud FAOR0, 2001, p. 142). Foram contemplados, com os respectivos lotes: era respeitável navegador e reconhecido pelos feitos nas conquistas de entrepostos portugueses na África e Índia, além de ser amigo do monarca, desde a infância, e primo-irmão de D. Antônio de Ataíde, o ministro das Finanças e o coordenador daquela reunião no Paço de Évora, donde se decidiu pelo sistema das capitanias. Aliás, do mesmo encontro fizeram parte o provedor-geral da Fazenda, Antônio Cardoso de Barros, o tesoureiro-geral do reino, Fernão Álvares de Andrade, e o secretário do Tesouro Real, Jorge de Figueiredo Correia. Por coincidência, todos eles também agraciados.

\begin{tabular}{|c|c|c|}
\hline Capitania & Donatários & Ofícios \\
\hline Maranhão $-1^{0}$ quinhão & João de Barros e Aires da Cunha & João de Barros - Fidalgo e feitor da Casa da Índia; Aires da Cunha - militar \\
\hline Maranhão & Fernão Álvares de Andrade & Funcionário da Coroa \\
\hline Ceará & António Cardoso de Barros & Funcionário da Coroa \\
\hline Ceará - $2^{\circ}$ quinhão & João de Barros e Aires da Cunha & Militar \\
\hline Itamaracá & Pero Lopes de Sousa & Fidalgo, militar e navegador \\
\hline Pernambuco & Duarte Coelho & Fidalgo \\
\hline Bahia & Francisco Pereira Coutinho & Funcionário da Coroa \\
\hline Ilhéus & Jorge de Figueiredo Correia & Militar \\
\hline Porto Seguro & Pero do Campo Tourinho & Lugar-tenente de Martim Afonso \\
\hline Espírito Santo & Vasco Fernandes Coutinho & Aristocrata e militar \\
\hline São Tomé & Pero de Góis & \\
\hline Rio de Janeiro & Martim Afonso de Sousa & \\
\hline Santo Amaro & Pero Lopes de Sousa & \\
\hline São Vicente & Martim Afonso de Sousa & Pero Lopes de Sousa \\
\hline Sant'Ana & & \\
\hline
\end{tabular}

Embora sem expoentes da alta nobreza, os integrantes da lista figuravam entre os cidadãos com posses, porque era obrigação do contemplado bancar 0 custo da viagem, 0 qual incluía, no mínimo, a aquisição e equipagem da nau e a compra das armas e provisões para a empreitada. Ao critério financeiro juntava-se 0 da familiaridade. Constavam na relação os irmãos Martim Afonso e Pero Lopes. 0 primeiro
Como unidades administrativas, as capitanias subsistiram até 1754, quando o Marquês de Pombal concluiu a transição das últimas propriedades privadas para o domínio estatal. Mas como forma de administração, este sistema foi substituído em seguida, em razão dos insucessos na colonização, do descaso de alguns donatários - quatro nem puseram os pés em suas propriedades -, e da intensificação das invasões 
francesas e espanholas. Em 1548, D. João III criou o governo-geral do Brasil e nomeou, em 7 de janeiro do ano seguinte, o militar e fidalgo Tomé de Sousa para o cargo. 0 primeiro governadorgeral do território brasileiro era, por sinal, primoirmão tanto de D. Antônio de Ataíde quanto de Martim Afonso de Sousa, e um dos seus feitos foi doar ao filho Garcia d'Ávila latifúndio gigantesco localizado na Bahia, daqueles mais largo "do que Estados de nossos dias" (FAOR0, 2001, p. 148).

Assim, o modelo das capitanias hereditárias como política estatal da colonização cedia lugar à centralização do governo-geral, mas legava a este e a outros modos posteriormente adotados 0 poder dos donos das grandes extensões de terra, da governança pelo nepotismo e compadrio, e do relacionamento estreito entre as lideranças locais e regionais com o poder central, materializada sob diversos modos: como a doação e foreamento de vastas propriedades naquela metade do século XVI, cuja analogia com os tempos de hoje seria a concessão de canais de rádio e televisão, tanto pelo poder executivo como pelo legislativo.

\section{Da genealogia das capitanias midiáticas}

A imprensa brasileira nasceu graças ao trabalho de parto realizado pelo poder executivo. Nos dois casos das publicações precursoras do jornalismo brasileiro - aquelas reconhecidas como tais pelo menos até agora - constata-se a presença estatal. 0 Correio Braziliense, editado por Hipólito José da Costa em Londres e cujo primeiro exemplar foi publicado em $1^{\circ}$ de junho de 1808 na capital britânica, recebeu no início e nos momentos de dificuldades financeiras a ajuda do duque de Sussex, filho do monarca inglês à época e responsável pela fuga de Hipólito da Costa do cárcere da Inquisição do Rossio de Lisboa, onde ficara detido entre 1802 e 1805 sob a acusação de fazer parte da irmandade maçônica Pedreiros-livres. "Augustus Frederiche, o duque de Sussex, filho de George III, o mais importante dos 'pedreiros-livres ingleses', era o chefe da maçonaria daquele país e foi 0 grande protetor de Hipólito na Inglaterra." (LUSTOSA, 2000, p. 75).

0 duque de Sussex foi padrinho do primeiro filho de Hipólito e o fez secretário para assuntos estrangeiros da Grande Loja da Inglaterra. No período anterior à prisão em Lisboa, Hipólito fazia parte do grupo de brasileiros protegidos por D. Rodrigo de Sousa Coutinho, sendo por este escolhido para fazer as viagens de expedição científica pelos Estados Unidos em 1798, quando D. Rodrigo ocupava a secretaria da Marinha e Ultramar, e nomeado diretor da Impressão Régia portuguesa em 1801 pelo então ministro do Erário Régio, D. Rodrigo. No Brasil, o conde de Linhares, no ministério dos Negócios Estrangeiros e da Guerra, coordenaria a Impressão Régia entre 1808 e 1812 e teria sob sua tutela o português Tibúrcio José da Rocha.

Em 10 de setembro de 1808 foi lançado no Rio de Janeiro o primeiro jornal editado em território brasileiro, a Gazeta do Rio de Janeiro, redigido 
pelo frei Tibúrcio. A publicação era editada na tipografia da Impressão Régia, no maquinário trazido a bordo do navio Medusa, na debandada da família real e corte portuguesa para fugir das tropas napoleônicas, no final de novembro de 1807. A criação da Impressão Régia em maio fora uma das primeiras providências de Dom João VI no Brasil e, a partir de 24 de julho do mesmo ano, passou a ser administrada por uma junta, da qual fazia parte um oficial da Secretaria de Negócios Estrangeiros e da Guerra.

Nem dois meses depois saía da gráfica a Gazeta do Rio de Janeiro, cuja propriedade era "dos oficiais da Secretaria de Estado dos Negócios Estrangeiros e da Guerra, que não só administravam como também tinham participação nos lucros da empresa" (LUSTOSA, 2000, p. 69). 0 dilema editorial - ser ou não ser governo - estendeu-se, para irritação dos opositores, até o suplemento da edição do dia 14 de dezembro de 1822, quando, no último parágrafo da segunda folha, apareceu a seguinte nota:

Noticia ao Publico: Tendo S. M. I. Sido Servido permittir que em lugar da actual Gazeta se publique hum Diário do Governo, annuncia-se que isto se executará do principio de janeiro próximo por diante, e que com a immediata Gazeta se publicará o Prospecto do referido Diário.

Em janeiro de 1823 nascia, oficialmente, a primeira publicação oficial do governo brasileiro, o Diário do Governo, parido da carne da Gazeta do Rio de Janeiro.

\section{0 compadrio na formação dos conglomerados midiáticos brasileiros: do pioneiro Diários Associados ao contemporâneo Organizações Globo.}

À intrincada relação umbilical entre Estado, iniciativa privada e imprensa acrescentam-se mais quatro episódios, envolvendo personagenschave nas histórias da política e dos meios de comunicação: Assis Chateaubriand, Carlos Lacerda, Getúlio Vargas, Roberto Marinho e Samuel Wainer. 0 já empresário da imprensa Francisco de Assis Chateaubriand, dono do matutino carioca $O$ Jornal e do vespertino paulista Diário da Noite, resolve, em 1927, antecipar-se à concorrência e fundar uma revista nacional. Sem capital, recorre a um amigo recente: 0 ministro da Fazenda do governo Washington Luís, Getúlio Dornelles Vargas.

Ao saber dos planos para a revista com 50 mil exemplares e circulação nas principais cidades do país, Getúlio, antevendo em Chatô um aliado para a campanha presidencial de 1930, pressionou o banqueiro Antônio Mostardeiro, proprietário do Banco da Província e nomeado por ele para o cargo de presidente do Banco do Brasil, para a concessão do empréstimo. "Coronel Antonico, nosso jornalista precisa de um empréstimo imediato de 500 contos de réis. Assim que 0 negócio dele começar a render, ele te paga. Eu garanto a operação", assegura o futuro presidente do Brasil (MORAIS, 1994, p. 178). Em 10 de dezembro de 1928 chegava às bancas, de Belém a Porto Alegre, o fruto do empréstimo concedido 
pelo Banco da Província, com o aval do ministro.

0 mesmo Getúlio Vargas seria 0 alvo do segundo fato. Deposto do poder em 1945 pelos militares, os quais o haviam levado à presidência na Revolução de 1930 e assegurado a imposição do golpe do Estado Novo em 1937, o estadista gaúcho recebe no Rio Grande do Sul a visita do jornalista Samuel Wainer, na época funcionário do jornal $A$ Noite, dos Diários Associados de Assis Chateaubriand, e anuncia naquela entrevista realizada no sábado do Carnaval de 1949 a disposição de retornar à política "mas não como líder de partidos, e sim como líder de massas" (WAINER, 2005, p. 28). A matéria, publicada em 3 de março, alvoroçou o cenário político e atiçou os antigetulistas, principalmente Carlos Lacerda.

0 jornalista e político da União Democrática Nacional arregimentou os pares e em dezembro de 1949 lançou a Tribuna de Imprensa, financiado com recursos udenistas. "Eu comprei por 700 cruzeiros o prédio onde funciona até hoje a Tribuna. E comprei à prestação, com o resto do dinheiro e mais um empréstimo que fiz no Banco de Crédito Real, onde era diretor o Luís Camilo, nomeado pelo Milton Campos." (LACERDA, 1978, p. 75). Luis Camilo era deputado e Milton Campos ministro unidenistas, e assim a Tribuna da Imprensa tornou-se 0 estandarte da visceral campanha contra 0 governo getulista.

Sem 0 apoio de um único grande jornal, Getúlio Vargas resolve contra-atacar. "Por que tu não fazes um jornal?", pergunta o presidente a
Samuel Wainer, o único repórter das grandes empresas jornalísticas presente à primeira reunião ministerial do novo governo, em 2 de fevereiro de 1951. Wainer aceita o desafio e, intermediado por Alzira Vargas, filha do presidente, consegue 30 mil cruzeiros em três cotas de 10, uma com o banqueiro Walter Moreira Salles, outra do empresário Euvaldo Lodi e a terceira com Ricardo Jafet, presidente do Banco do Brasil e integrante da família proprietária do Banco Cruzeiro do Sul, de onde saiu o dinheiro. Para assegurar os primeiros meses do Última Hora, Wainer ainda conta com 0 auxílio do recém-eleito governador de Minas Gerais, Juscelino Kubitschek, para obter o empréstimo de 3 milhões de cruzeiros com 0 Banco Hipotecário de Crédito Real (WAINER, 2005, p. 155-159). Em 12 de junho de 1951 era lançado o primeiro exemplar do Última Hora. Na capa, uma carta do presidente a Samuel Wainer (WAINER, 2005, p. 185-187).

0 sucesso da publicação defensora do governo popular-populista de Getúlio Vargas provocou a imediata reação dos proprietários das empresas de comunicação, em especial Carlos Lacerda, Assis Chateaubriand e Roberto Marinho.

Passaram a atacar por terra, ar e mar. Lacerda, pelo talento da oratória e pela explícita ojeriza a Wainer e Vargas, assumiu a linha de frente da campanha, respaldado por Chatô e Marinho. 0 primeiro cedeu a Lacerda espaço na recém-criada TV Tupi, aproveitando o potencial do novo meio havia pouco implantado no Brasil, e o segundo 
reservava expressivo tempo na rádio Globo para os ataques de Lacerda.

Mesmo sendo também devedores dos cofres públicos (LAURENZA, 1998, p. 170-171), com créditos sob condições amigáveis semelhantes às obtidas por Wainer, os três pressionaram até conseguir a primeira Comissão Parlamentar de Inquérito da imprensa brasileira, instalada em março de 1953. A CPI foi aprovada com 0 argumento de averiguar a concessão de empréstimos ilícitos a empresas jornalísticas. Entretanto, sob a coordenação da UDN e complacência dos parlamentares governistas, a comissão direcionou as investigações contra Samuel Wainer e as possíveis benesses recebidas do governo Vargas. Como resultado das investigações, retaliações ao primeiro, o desgaste político do segundo e a semeadura do explosivo cenário político, do qual resultariam 0 atentado à vida de Carlos Lacerda, em 5 de agosto de 1954, a pressão dos comandantes das Forças Armadas para a renúncia do presidente e o suicídio de Getúlio Vargas na madrugada do dia 24 de agosto.

0 quarto episódio ilustrativo do secular compadrio entre o Estado e a imprensa comporta o fator propulsor para as Organizações Globo tornarem-se uma das maiores empresas midiáticas do mundo, abrange o período correspondente à semeadura e consolidação do golpe militar efetuado em 1964, antecipa a política das telecomunicações a ser adotada pelo regime militar do favorecimento dos grupos com os quais contou para firmar-se e mostra quão cambiantes são as alianças firmadas entre os senhores da mídia brasileira. Iniciou-se em 1961 a aproximação do empresário Roberto Marinho - na época proprietário do jornal $O$ Globo, da editora Rio Gráfica e da rádio Globo, pela qual conseguira neste mesmo ano a concessão para um canal de televisão - com o poderoso grupo norte-americano Time-Life, dono de 5 emissoras de televisão e das revistas Time, Fortune e Life. Em 26 de abril de 1965, estreia a TV Globo, com os aportes tecnológico e financeiro da empresa norte-americana oriundos da sociedade constituída em 28 de junho de 1962.

Em depoimento numa cadeia de rádio e televisão, o deputado João Calmon revelou que, 'de fevereiro até novembro de 1965, o grupo TimeLife tinha remetido ao grupo Roberto Marinho (TV GLOBO) nada menos que 2.838.613,28 dólares, correspondendo, em moeda brasileira, a, aproximadamente, 6 bilhões e 145 milhões de cruzeiros! Uma média de quase 700 milhões por mês!' (SODRÉ, 1999, p. 439).

A "cadeia de rádio e televisão" referida era a dos Diários e Emissoras Associados e o deputado federal João Calmon era um dos diretores da rede de Assis Chateaubriand. 0 empresário agora se voltava contra 0 antigo aliado porque se esboçava 0 surgimento de um grupo forte capaz de equiparar-se ao poder do poderoso proprietário do maior grupo de comunicação da época e, além disso, a Time-Life concorria com a revista $O$ Cruzeiro no mercado latino-americano. Assis Chateaubriand passou a contar com 0 apoio de Carlos Lacerda, agora governador da 
Guanabara e em litígio com Roberto Marinho em razão das desavenças e críticas ao governo proferidas pelo $O$ Globo e a Rádio Globo. 0 calcanhar de Aquiles do acordo Globo/Time-Life era a participação acionária do grupo estrangeiro em empresa jornalística, proibida no artigo 160 da constituição brasileira.

Pressionado principalmente pela campanha do conglomerado de Chatô, o marechal-presidente Humberto Castelo Branco determina, em 20 de janeiro de 1966, a criação da Comissão de Alto Nível, vinculada ao Ministério da Justiça, para investigar as denúncias da ingerência do capital estrangeiro em empresas jornalísticas, em especial o caso da Globo. Dois meses depois o governo militar avaliza o congresso para investigar o contrato e em 30 de março de 1966 é oficializada a CPI Globo/Time-Life, com 10 integrantes da governista Aliança Renovadora Nacional (Arena) e cinco do oposicionista Movimento Democrático Brasileiro (MDB). Quatro meses depois foi aprovado o parecer do relator condenando os contratos e sugerindo "ao Poder Executivo aplicar à empresa faltosa a punição legal pela infringência daquele dispositivo constitucional" (HERZ, 1991, p. 183).

Porém, a aventada punição sugerida ao poder executivo desvaneceu-se nas averiguações da comissão do Ministério da Justiça, nos pareceres do Conselho Nacional das Telecomunicações (Contel), nos recursos da Globo contra as sugestões do Contel para readequações do contrato e nas considerações da Consultoria Geral da República. Por fim, em despacho da Presidência da República, assinado pelo general Arthur da Costa e Silva em 23 de setembro de 1968, o contrato é reconhecido como legal.

Os contratos celebrados entre TV-Globo e Time-Life, depois de exaustivamente examinados pelo Conselho Nacional das Telecomunicações e pela Comissão de Alto Nível, nomeada pela Portaria $n^{0}$ 22-B, de 24.1.66, do Senhor Ministro da Justiça, foram submetidos a esta Consultoria Geral para estudo e parecer. 2. Neste órgão emitiu-se o Parecer $n^{\circ} 490-\mathrm{H}$, sobre 0 assunto, 0 qual foi aprovado pelo Excelentíssimo Senhor Presidente da República da forma que se segue: ' 0 parecer do Sr. Consultor-Geral da República chega à conclusão da validade dos contratos em exame, por não haverem eles infringido qualquer dispositivo da lei vigente à época de sua celebração' (HERZ, 1991, p. 293).

Assim, reforçada a influência no poder executivo - explicitada pela nomeação do seu advogado no caso Time-Life, Luiz Gonzaga do Nascimento e Silva, como ministro do Trabalho e da Previdência Social, ainda no governo Castelo Branco, e depois como titular do Ministério da Previdência Social, no mandato do general Ernesto Geisel -, Roberto Marinho manteve a parceria com o grupo Time-Life até julho de 1971 (MEMÓRIA GLOBO, 2008), investiu no aprimoramento tecnológico da emissora, adotou o know-how norte-americano na programação, inovou na adoção da transmissão televisiva em rede, apoiou a política do regime militar na área das telecomunicações, expandiu a empresa com novas aquisições e afiliações nas principais capitais e cidades brasileiras, 
formando a maior capitania midiática do país a partir da década de 1970: as Organizações Globo, como sintetizara João Calmon:

Que representava a Organização Roberto Marinho no setor de rádio deste país? Esse grupo possuía a Rádio Globo e, há cerca de um ou dois anos, adquiriu a Rádio Eldorado, do Rio de Janeiro, e também uma pequena estação de Petrópolis, se não me engano a Rádio Imperial. E só. Depois de iniciadas essas démarches com um grupo estrangeiro, que já lhe remeteu oficialmente 8 bilhões de cruzeiros, e através de filmes mais dois, três ou quatro bilhões, a TV Globo partiu para inaugurar sua estação de televisão no Rio de Janeiro. Comprou em São Paulo a TV Nacional, a TV Paulista, canal 5, a Rádio Nacional, a Rádio Excelsior, a TV Bauru; adquiriu em Porto Alegre uma estação de rádio [...] e adquiriu em Recife [...] cinco estações de rádio [...] E mais do que isso [...] (HERZ, 1991, p. 196).

\section{Considerações finais}

As reticências inseridas no final da citação anterior não fazem parte da mesma, mas foram intencionalmente colocadas para figurar o quanto João Calmon alongar-se-ia para ilustrar 0 crescimento das empresas de Roberto Marinho a partir do episódio Globo/ Time-Life e, a partir disso, o quanto também as Organizações Globo tornaram-se objeto de relevantes estudos para a comunicação e 0 jornalismo brasileiro, como se pode citar nas reflexões e investigações desenvolvidas, por exemplo, por estudiosos como Bolaños, Brittos, Caparelli, Herz, Lima, Santos e por entidades tais qual o Instituto de Estudos e Pesquisas em Comunicação (EPCOM).
Ao utilizar a referida pontuação, este estudo delimita até onde pretendeu abordar, sem deixar de incitar a prolongamentos sobre 0 assunto. Portanto, delimitou-se este trabalho a, aproveitando-se da existência das capitanias hereditárias na colonização brasileira, fazer a devida analogia para mostrar o inerente compadresco entre o público e o privado, presente tanto na distribuição territorial e iniciativas da ocupação do Brasil quanto na formação dos principais conglomerados midiáticos, dos quais foram aqui mencionados os Diários Associados, de Assis Chateaubriand - conhecido no auge das empresas como o Rei do Brasil -, e as Organizações Globo cujo proprietário, de vez em quando, em arroubos à Luís XIV, dizia: "Eu sou o poder".

\section{Referências}

ABREU, Alzira Alves de et al. Dicionário

histórico-biográfico brasileiro. Rio de Janeiro: FGV, 2001.

ABREU, Capistrano de. Capítulos de história colonial. 7. ed. Belo Horizonte: Itatiaia; São Paulo: Publifolha, 2000.

BARBOSA, Marialva. História cultural da imprensa - Brasil: 1900-2000. Rio de Janeiro: Mauad X, 2007.

BAYMA, Israel Fernando de Carvalho. A concentração da propriedade de meios de comunicação e o coronelismo eletrônico no

Brasil. Brasília: Assessoria técnica do Partido dos Trabalhadores, nov. 2001. Disponível em: <http:// 
www.assessoriadopt.org/concentracao.pdf>. Acesso em: 10 mar. 2009.

BIAL, Pedro. Roberto Marinho. Rio de Janeiro: Jorge Zahar, 2004.

BUENO, Eduardo. Capitães do Brasil: a saga dos primeiros colonizadores. 2. ed. Rio de Janeiro: Objetiva, 2006.

\section{CASTR0, Cosette et al. Cartografia audiovisual}

brasileira de 2005. São Leopoldo, Unisinos, 2006. Disponível em: http://itvproducoesinterativas. com.br/pdfs/relatorios/cartograia.pdf. Acesso em: 10 mar. 2009.

CHAGAS, Carlos. 0 Brasil sem retoque: 18081964 - a história contada por jornais e jornalistas. Rio de Janeiro: Record, 2001. 2 v.

COSTA, Sylvio; BRENER, Jayme. Coronelismo eletrônico: 0 governo Fernando Henrique e 0 novo capítulo de uma velha história. Correio Braziliense, maio-agosto 1997. Observatório da Imprensa, São Paulo, 20 ago. 1997. Disponível em: <http://observatoriodaimprensa.com.br/ artigos/mat2008.htm>. Acesso em: 10 mar. 2009.

EGYPTO, Luiz. Quem são os donos da mídia no Brasil. Observatório da Imprensa, São Paulo, 24 abr. 2002. Disponível em: <http:// www.observatoriodaimprensa.com.br/cadernos/ cid240420021.htm>. Acesso em 10 mar. 2009.

FAOR0, Raymundo. Os donos do poder: formação do patronato político brasileiro. 3. ed. São Paulo: Globo, 2001.
FAUSTO, Boris. História do Brasil. 11. ed. São

Paulo: Edusp, 2003.

FREYRE, Gilberto. Casa-grande e senzala. 43. ed. Rio de Janeiro: Record, 2001.

FURTAD0, Celso. Formação econômica do

Brasil. 34. ed. São Paulo: Editora Nacional, 2005.

HERZ, Daniel. A história secreta da Rede

Globo. Porto Alegre: Ortiz, 1991.

HOHLFEDT, Antonio; Buckup, Carolina. Ultima

Hora: populismo nacionalista nas páginas de um jornal. Porto Alegre: Sulina, 2002.

HOLANDA, Sérgio Buarque de (org.). História geral da civilização brasileira - Tomo I. 2. ed.

São Paulo: Difusão Europeia do Livro, 1963.

HOLANDA, Sérgio Buarque de. Raízes do Brasil.

São Paulo: Companhia das Letras, 1995.

LAGO, Cláudia; ROMANCINI, Richard. História do jornalismo no Brasil. Florianópolis: Insular, 2007.

LAURENZA, Ana Maria de Abreu. Lacerda x

Wainer: 0 Corvo e Bessarabiano. 2. ed. São Paulo: Senac. 1998.

LIMA, Venício A. de. Mídia: crise política e poder no Brasil. São Paulo: Perseu Abramo, 2006.

As bases do novo coronelismo

eletrônico. Observatório da Imprensa, São

Paulo, n. 341, ago. 2005. Disponível em: <http:// observatorio.ultimosegundo.ig.com.br/artigos. asp?cod=341IPB001 $>$. Acesso em: 10 mar. 2009. 
LUSTOSA, Isabel. Insultos impressos: a guerra dos jornalistas na independência. São Paulo: Companhia das Letras, 2000.

MARTINS, Ana Luiza; LUCA, Tânia Regina de.

História da imprensa no Brasil. São Paulo: Contexto, 2008.

\section{MATTOS, Sérgio. História da televisão}

brasileira: uma visão econômica, social e política. 2. ed. Petrópolis: Vozes, 2002.

\section{MEMÓRIA GLOBO. Polêmicas históricas:}

concessões de canais (1957 e 1962). Rio de Janeiro, 7 jul. 2008. Disponível em: <http://memoriaglobo. globo.com/Memoriaglobo/0,27723,5270-p-21891,00. html>. Acesso em: 10 mar. 2009.

Polêmicas históricas: 0 caso Time-

Life (1962-1971). Rio de Janeiro, 7 jul. 2008.

Disponível em: <http://memoriaglobo.globo.com/ Memoriaglobo/0,27723,5270-p-21890,00.html>. Acesso em: 10 mar. 2009.

MORAIS, Fernando. Chatô: o rei do Brasil. São

Paulo: Companhia das Letras, 1994.

NETTO, Accioly. 0 império de papel: os bastidores de 0 Cruzeiro. Porto Alegre: Sulina, 1998.

PIERANTI, Octavio Penna. Políticas públicas para radiodifusão e imprensa. Rio de Janeiro:

Fundação Getúlio Vargas, 2007.

RIBEIR0, Darcy. 0 povo brasileiro: a formação e sentido do Brasil. 2. ed. São Paulo: Companhia das Letras, 2004.
SANTOS, Suzy; CAPARELLI, Sérgio. Coronelismo, radiodifusão e voto: a nova face de um velho conceito. In: BRITTOS, Valério Cruz; BOLAÑO, César (orgs.). Rede Globo: 40 anos de poder e hegemonia. v. 1. São Paulo: Paulus, 2005. p. 77-101.

SANTOS, Suzy dos. E-Sucupira: o coronelismo eletrônico como herança do coronelismo nas comunicações brasileiras. E-Compós, Brasília, v. 7, dez. 2006. Disponível em: <http://www. compos.org.br/seer/index.php/e-compos/article/ view/104/103>. Acesso em: 10 mar. 2009.

SCHIRMER, Lauro. RBS: da voz-do-poste à multimídia. Porto Alegre: L\&PM, 2002.

SENADO FEDERAL. Concentração da mídia: debates no Conselho de Comunicação Social. Brasília: Congresso Nacional, 2004.

SILVA, Arlindo. A fantástica história de Silvio

Santos. São Paulo: Editora do Brasil, 2002.

SILVA, Hélio. 1954: um tiro no coração. Porto Alegre: L\&PM, 2007.

SKIDMORE, Thomas E. Uma história do Brasil. São Paulo: Paz e Terra, 1998.

SODRÉ, Nelson Werneck. História da imprensa no Brasil. 4. ed. Rio de Janeiro: Mauad, 1999. TAVOLARO, Douglas; LEMOS, Christina. 0 bispo: a história revelada de Edir Macedo. São Paulo: Larousse do Brasil, 2007.

WAINER, Samuel. Minha razão de viver. São Paulo: Planeta, 2005. 


\section{Sites:}

http://donosdamidia.com.br

http://www.fndc.org.br

http://www.acessocom.com.br 


\section{Friendship in the formation of Brazilian media hereditary capitanies}

\section{Abstract}

This paper starts from an analogy between the inherited captaincys policys that were adopted for the Portuguese crown as a process of colonization of the Brazilian territory in the 16th century and its distribution related to family related people with the royal power with nowadays press. This paper highlights the presence of beneficts and affilitaions between the public State and journalism from the beggining of the Brazilian press with Gazeta do Rio de Janeiro and Correio Braziliense in 1808 to contemporary cases of midiatic conglomerates, for instance Diários Associados and Organizaçoes Globo. Our main goal is to show how questionable is the independence and freewill rhetoric of Brazilian media.

\section{Keywords}

Friendship. Hereditary captaincies. Brazilian media. Journalism. Formation.

\section{El amiguismo en la formación de las capitanías hereditarias de los media brasileños}

\section{Resumen}

A partir de, como analogía, la política de capitanías, aprobada por la corona portuguesa como un proceso de colonización del territorio brasileño en el siglo XVI y su distribución, según el patrocinio y el parentesco con el poder real, este artículo pone de relieve la presencia de amiguismo entre el gobierno y el periodismo en la génesis de la prensa en Brasil, con Gazeta do Rio de Janeiro y Correio Braziliense, en 1808, a los conglomerados de los medios contemporáneos. Aquí son presentados los casos de los Diários Associados y, en particular, de Organizações Globo. El objetivo es enseñar cómo fueron y son cuestionables la retórica de la tan anunciada independencia como señalan los medios de comunicación y la prensa brasileña.

\section{Palabras clave}

Amiguismo. Capitanías. Los medios de comunicación brasileños. Periodismo. Formación. 


\section{Expediente}

A revista E-Compós é a publicação científica em formato eletrônico da Associação Nacional dos Programas de Pós-Graduação em Comunicação (Compós). Lançada em 2004, tem como principal finalidade difundir a produção acadêmica de pesquisadores da área de Comunicação, inseridos em instituições do Brasil e do exterior.
E-COMPÓS I www.e-compos.org.br I E-ISSN 1808-2599

Revista da Associação Nacional dos Programas de Pós-Graduação em Comunicação. Brasília, v.12, n.3, set./dez. 2009

A identificação das edições, a partir de 2008 passa a ser volume anual com três números.

\section{CONSELHO EDITORIAL}

Afonso Albuquerque

Universidade Federal Fluminense, Brasil

Alberto Carlos Augusto Klein

Universidade Estadual de Londrina, Brasi

Alex Fernando Teixeira Primo

Universidade Federal do Rio Grande do Sul, Brasil

Alfredo Vizeu

Universidade Federal de Pernambuco, Brasi

Ana Carolina Damboriarena Escosteguy

Pontifícia Universidade Católica do Rio Grande do Sul, Brasil

Ana Silvia Lopes Davi Médola

Universidade Estadual Paulista, Brasil

André Luiz Martins Lemos

Universidade Federal da Bahia, Brasil

Ângela Freire Prysthon

Universidade Federal de Pernambuco, Brasil

Antônio Fausto Neto

Universidade do Vale do Rio dos Sinos, Brasil

Antonio Carlos Hohlfeldt

Pontifícia Universidade Católica do Rio Grande do Sul, Brasil

Arlindo Ribeiro Machado

Universidade de São Paulo, Brasil

César Geraldo Guimarães

Universidade Federal de Minas Gerais, Brasi

Cristiane Freitas Gutfreind

Pontifícia Universidade Católica do Rio Grande do Sul, Brasil

Denilson Lopes

Universidade Federal do Rio de Janeiro, Brasil

Eduardo Peñuela Cañizal

Universidade Paulista, Brasil

Erick Felinto de Oliveira

Universidade do Estado do Rio de Janeiro, Brasil

Francisco Menezes Martins

Universidade Tuiuti do Paraná, Brasil

Gelson Santana

Universidade Anhembi/Morumbi, Brasil

Goiamérico Felício

Universidade Federal de Goiás, Brasil

Hector Ospina

Universidad de Manizales, Colômbia

Herom Vargas

Universidade Municipal de São Caetano do Sul, Brasil

leda Tucherman

Universidade Federal do Rio de Janeiro, Brasil

Itania Maria Mota Gomes

Universidade Federal da Bahia, Brasil

Janice Caiafa

Universidade Federal do Rio de Janeiro, Brasil

Jeder Silveira Janotti Junior

Universidade Federal da Bahia, Brasil

\section{João Freire Filho}

Universidade Federal do Rio de Janeiro, Brasil

John DH Downing

University of Texas at Austin, Estados Unidos

José Luiz Aidar Prado

Pontifícia Universidade Católica de São Paulo, Brasil

José Luiz Warren Jardim Gomes Braga

Universidade do Vale do Rio dos Sinos, Brasi

Juremir Machado da Silva

Pontifícia Universidade Católica do Rio Grande do Sul, Brasil

Lorraine Leu

University of Bristol, Grã-Bretanha

Luiz Claudio Martino

Universidade de Brasília, Brasil

Maria Immacolata Vassallo de Lopes

Universidade de São Paulo, Brasil

Maria Lucia Santaella

Pontifícia Universidade Católica de São Paulo, Brasil

Mauro Pereira Porto

Tulane University, Estados Unidos

Muniz Sodre de Araujo Cabral

Universidade Federal do Rio de Janeiro, Brasil

Nilda Aparecida Jacks

Universidade Federal do Rio Grande do Sul, Brasil

Paulo Roberto Gibaldi Vaz

Universidade Federal do Rio de Janeiro, Brasil

Renato Cordeiro Gomes

Pontifícia Universidade Católica do Rio de Janeiro, Brasil

Ronaldo George Helal

Universidade do Estado do Rio de Janeiro, Brasil

Rosana de Lima Soares

Universidade de São Paulo, Brasil

Rossana Reguillo

Instituto Tecnológico y de Estudios Superiores do Occidente, México

Rousiley Celi Moreira Maia

Universidade Federal de Minas Gerais, Brasil

Samuel Paiva

Universidade Federal de São Carlos, Brasil

Sebastião Albano

Universidade Federal do Rio Grande do Norte, Brasil

Sebastião Carlos de Morais Squirra

Universidade Metodista de São Paulo, Brasil

Simone Maria Andrade Pereira de Sá

Universidade Federal Fluminense, Brasi

Suzete Venturelli

Universidade de Brasília, Brasil

Valério Cruz Brittos

Universidade do Vale do Rio dos Sinos, Brasil

Veneza Mayora Ronsini

Universidade Federal de Santa Maria, Brasil

Vera Regina Veiga França

Universidade Federal de Minas Gerais, Brasi

\section{COMISSÃO EDITORIAL}

Felipe da Costa Trotta I Universidade Federal de Pernambuco, Brasil Rose Melo Rocha I Escola Superior de Propaganda e Marketing, Brasil

\section{CONSULTORES AD HOC}

Arthur Autran Franco de Sá Neto I Universidade Federal de São Carlos

Carlos Eduardo Franciscato I Universidade Federal de Sergipe

Elisa Reinhardt Piedras I Universidade Federal do Rio Grande do Sul

Elizabeth Bastos Duarte I Universidade Federal de Santa Maria

Marcia Benetti Machado I Universidade Federal do Rio Grande do Sul

Sandra Maria Lúcia Pereira Gonçalves I Universidade Federal do Rio Grande do Sul

Suzana Kilpp I Universidade do Vale do Rio dos Sinos

Tattiana Gonçalves Teixeira I Universidade Federal de Santa Catarina

Vander Casaqui I Escola Superior de Propaganda e Marketing

Vicente Gosciola I Universidade Anhembi Morumb

Walter Teixeira Lima Junior I Fundação Cásper Líbero

REVISÃO DE TEXTO E TRADUÇÃO I Everton Cardoso

EDITORAÇÃO ELETRÔNICA I Raquel Castedo
COMPóS I www.compos.org.br

Associação Nacional dos Programas de Pós-Graduação em Comunicação

Presidente

Itania Maria Mota Gomes

Universidade Federal da Bahia, Brasil

itania@ufba.br

Vice-presidente

Julio Pinto

Pontifícia Universidade Católica de Minas Gerais, Brasil

juliopinto@pucminas.br

Secretária-Geral

Ana Carolina Escosteguy

Pontifícia Universidade Católica do Rio Grande do Sul, Brasil

carolad@pucrs.br 